\title{
Análisis estructural de la fibrina rica en plaquetas y sus aplicaciones en
} odontología regenerativa*

Structural Analysis of Platelet-Rich Fibrin and its Applications in Regenerative Dentistry

Recibido para publicación: 28-05-2018 | Aceptado para publicación: 30-12-2018

\section{DAVID ALEXANDER GUTIÉRREZ RAMÍREZ}

Universidad Antonio Nariño, Popayán, Colombia. davigutierrez@uan.edu.co. https://orcid.org/0000-0002-8921-1327

\section{Juan Pablo Hinojosa SARria}

Universidad Antonio Nariño, Popayán, Colombia. jphinojosa@uan.edu.co. https://orcid.org/0000$\underline{0001-7410-9007}$

\author{
ANA IsABEL RESTREPo DORADO \\ Universidad Antonio Nariño, Popayán, Colombia. anare@uan.edu.co. https://orcid.org/0000- \\ $\underline{0001-7900-9638}$
}

\begin{abstract}
ANa Luisa Muñoz Ramírez
Universidad Antonio Nariño, Bogotá, Colombia. analuisa.munoz@uan.edu.co. https://orcid.org/0000-0002-7566-2979
\end{abstract}


NÉSTOR FABIÁn VELARde Trochez

Universidad Antonio Nariño, Popayán, Colombia. nvelarde@uan.edu.co. https://orcid.org/0000-

$\underline{0002-5358-7912}$

\section{FrANCY ESTER BASTIDAS DAZA}

Universidad Antonio Nariño, Popayán, Colombia. fbastidas@ uan.edu.co. https://orcid.org/0000-

$\underline{0002-0725-683 X}$

*Investigacion original.

${ }^{a}$ Correspondencia: davigutierrez@uan.edu.co

doi: https://doi.org/10.11144/Javeriana.uo37-79.aefr

Cómo citar: Gutiérrez Ramirez DA, Hinojosa Sarria JP, Restrepo Dorado AI, Muñoz Ramírez AL, Velarde trochez NF, Bastidas Daza FE. Análisis estructural de la fibrina rica en plaquetas y sus aplicaciones en odontología regenerativa. Univ Odontol. 2018 jul-dic; 37(79). https://doi.org/10.11144/Javeriana.uo37-79.aefr 


\section{RESUMEN}

Antecedentes: La fibrina rica en plaquetas (PRF) es un concentrado plaquetario que se está usando con mayor frecuencia en medicina y odontología. Los resultados clínicos son variables posiblemente porque hay diferentes protocolos de obtención, equipos de centrifugado y técnicas de colocación. El desconocimiento de los aspectos estructurales puede afectar el resultado clínico. Objetivo: Describir las características estructurales de la PRF en las diferentes zonas de la membrana. Métodos: Se realizó un estudio experimental in vitro con 15 muestras de sangre periférica tomada de cinco voluntarios adultos, sanos, asistentes a la clínica odontológica de la Universidad Antonio, Popayán. Se hizo hemograma inicial, se recolectó sangre y se centrifugó (10 min x 3000 rpm). Las muestras se analizaron histológicamente y con microscopía electrónica de barrido (SEM). Se describió la estructura de la fibrina, las plaquetas y los leucocitos. Resultados: El promedio de recuento de plaquetas en sangre total fue de $251 \pm 31,74$ x 103 x mm3 y en PRF fue de $832 \pm 123,43$ x103 x mm3. Macroscópicamente, se identificaron tres zonas del PRF: una superior con pocas plaquetas, una zona leucocitaria $(\mathrm{BC})$ y una zona corpuscular roja. En el análisis de microscopía óptica muestra que en la zona BC hay mayor concentración plaquetaria. El análisis por SEM comprueba que la estructura de la red de fibrina y el contenido celular son diferenciales en cada zona. Conclusión: A partir del conocimiento estructural del PRF se pueden proponer aplicaciones que mejoren el rendimiento del material y por tanto los resultados clínicos.

\section{Palabras clave}

concentrados plaquetarios, fibrina rica en plaquetas; microscopía electrónica de barrido 


\section{Áreas temáticas}

regeneración tisular; odontología; odontología regenerativa

\section{ABSTRACT}

Background: Platelet rich fibrin (PRF) is a platelet concentrate that is used most frequently in medicine and dentistry. Clinical results are variables because there are different protocols, centrifugation equipment and placement techniques. Ignorance of structural elements can affect the clinical outcome. Purpose: To describe the structural characteristics of Platelet Rich Fibrin in the different zones of the membrane. Methods: Experimental in vitro study with 15 blood samples taken from five healthy adult volunteers attending the dental clinic of the University Antonio Nariño, Popayán. The basal blood count was made, then blood was collected and centrifuged (10 minutes x $3000 \mathrm{rpm})$. The samples were analyzed histologically and with scanning electron microscopy (SEM). The structure of fibrin, platelets and leukocytes was described. Results: The average platelet count in whole blood was $251 \pm 31.74 \times 10^{3} \mathrm{x} \mathrm{m}^{3}$ and in PRF it was $832 \pm 123.43 \times 10^{3} \times \mathrm{mm}^{3}$. Macroscopically, three areas of the PRF were identified: an upper one with few platelets (FPP), a buffy coat (BC) and the corpuscular network zone (RBC). In the analysis of optical microscopy shows that in the $\mathrm{BC}$ area there is a higher platelet concentration. The SEM analysis proves that the structure of the fibrin network and cellular content is differential in each zone. Conclusion: From the structural knowledge of the PRF, applications that may be improve the performance of the biomaterial and therefore the clinical results can be proposed.

\section{Keywords}


platelet concentrates; platelet rich fibrin; scanning electron microscopy

\section{Thematic fields}

dentistry; tissue regeneration; regenerative dentistry

\section{INTRODUCCIÓN}

En los últimos años, se han desarrollado técnicas nuevas mínimamente invasivas para la obtención de biomateriales usados en terapias odontológicas regenerativas y basadas en conceptos de ingeniería tisular (1). Recientemente, en algunos procedimientos de cirugía oral y maxilofacial, periodoncia y endodoncia se usan técnicas que utilizan derivados sanguíneos conocidos como concentrados plaquetarios, que se aplican solos o en combinación con otros materiales para mejorar su efecto (2-6).

La fibrina rica en plaquetas (PRF) es un concentrado plaquetario que se define como un biomaterial autólogo, libre de anticoagulantes y químicos externos(7). Se obtiene en un sólo proceso de centrifugación de sangre periférica, en el que se forma una red de fibrina con una alta concentración de plaquetas y leucocitos, que secretan biomoléculas claves en el proceso de reparación y/o regeneración de tejidos (8). Aunque se han identificado algunos mecanismos moleculares que se activan cuando el PRF entra en contacto con los tejidos, existen aspectos estructurales que no están completamente claros, asociados con el proceso de obtención (9).

La técnica de obtención de PRF se fundamenta en la migración de los componentes sanguíneos

por fuerza gravitacional, lo que genera variabilidad en la estructura del PRF cuando se realiza el 
mismo protocolo de centrifugación con diferentes equipos (10). Al igual que el plasma rico en plaquetas (PRP), desde el desarrollo del PRF hasta ahora, se han reportado diferentes protocolos de centrifugación en la literatura, principalmente enfocados en modificar el tiempo (de 8 a 12 minutos) y la velocidad (de 2500 a $3200 \mathrm{rpm}$ ) lo que genera diferentes resultados en los concentrados y por ende resultados clínicos variables, posiblemente asociados a los cambios estructurales $(11,12)$.

La alteración de la red fibrina y los cambios en la cantidad de plaquetas contenidas en PRF puede afectar los resultados in situ, debido a que existe una correlación entre conteo de plaquetas en el PRF y la expresión de factores de crecimiento (9). Lo que hace necesario estandarizar el protocolo de obtención según el equipo disponible y las aplicaciones biomédicas, para identificar los patrones de distribución celular dentro de la red de fibrina y así garantizar la calidad del biomaterial para que pueda ser aplicado eficientemente en las diferentes necesidades clínicas odontológicas con éxito y menor variabilidad en los resultados clínicos. El objetivo de este estudio es describir las características estructurales de la Fibrina Rica en Plaquetas en las diferentes zonas de la membrana.

\section{MATERIALES Y MÉTODOS}

Se realizó un estudio experimental in vitro con 15 muestras de sangre periférica tomadas de cinco voluntarios adultos sanos, asistentes a la clínica Odontológica de adulto de la Universidad Antonio, sede Popayán, con edades entre 18 y 40 años, sin antecedentes de ingesta de aspirina o medicamentos que afecten la coagulación. Todos aceptaron participar voluntariamente en el 
presente estudio con la firma del consentimiento informado. El proyecto fue debidamente aprobado por el comité de ética de la Universidad Antonio Nariño y se ejecutó según la normatividad mundial de investigación en salud.

A cada voluntario se le hizo hemograma completo para determinar los valores basales respectivos. Luego, de cada paciente se tomaron $15 \mathrm{ml}$ de sangre de la vena antecubital, colectados en tubos de $6 \mathrm{ml}$ (Becton Dickinson, NJ, EE.UU.), los cuales fueron inmediatamente procesados en la centrífuga digital (SCILogex $®$ DMO 412) con el protocolo de centrifugado de 10 minutos y 3.000 rpm para obtener finalmente un total 15 muestras de $\operatorname{PRF}(7)$, de las cuales 10 fueron compactadas inmediatamente con la tapa de la caja de PRF durante 1 minuto para convertirlas en membranas (13). Las otras 5 muestras de PRF no se compactaron y se analizaron en gel, tal como salieron del tubo.

Todas las muestras, tanto gel como membranas, se fijaron en glutaraldehído al $4 \%$ y posteriormente se deshidrataron en soluciones de concentraciones crecientes de etanol. Luego se seccionaron sagitalmente en dos partes, la primera se incluyó en parafina para ser seccionada cada $6 \mu \mathrm{m}$ en micrótomo (Leica RM2125) y finalmente ser teñidas con tricrómico de Masson. Los cortes se analizaron en el microscopio óptico Leica DM2500 en la Universidad Antonio Nariño, sede Bogotá. La segunda sección se deshidrató como se mencionó anteriormente, se metalizó con 20nm de oro (Quorum, Q150R ES, UK) la observación se realizó con el microscopio electrónico (FEI, Quanta 200-r EE UU) en el laboratorio de microscopia electrónica de barrido de la Universidad Nacional de Colombia, Bogotá. Las fotografías se tomaron con 15-20 Kv, con aumentos de $1.000 \mathrm{x} 5.000$ y $8.000 x$. 


\section{RESULTADOS}

El promedio de recuento de plaquetas basales, en sangre total, de los voluntarios evaluados fue de $251 \pm 21,54 \times 10^{3} \times \mathrm{mm}^{3}$, en PRF fue de $832 \pm 123,43 \times 10^{3} \mathrm{x} \mathrm{mm}^{3}$. Todos los voluntarios tuvieron los parámetros del hemograma dentro de los rangos normales.

\section{Características macroscópicas}

Las membranas de PRF obtenidas no presentaron diferencias macroscópicas en cuanto a color y textura entre pacientes. Se obtuvieron membranas de PRF ligeramente de mayor tamaño de los voluntarios más jóvenes.

Se pudo identificar tres zonas en la membrana de PRF: una superior de color ámbar claro con una textura suave con una estructura de fibrina con pocas plaquetas (FPP, por su sigla en inglés), una zona intermedia más densa de color ámbar oscuro, denominada capa de leucocitos (BC, por su abreviatura en inglés) y una tercera zona, en la parte inferior de color rojo oscuro conocida como zona corpuscular roja (RBC, por su sigla en inglés) (figura 1). 
FIGURA 1. ZONAS DE LA MATRIZ DE FIBRINA RICA EN PLAQUETAS (PRF)
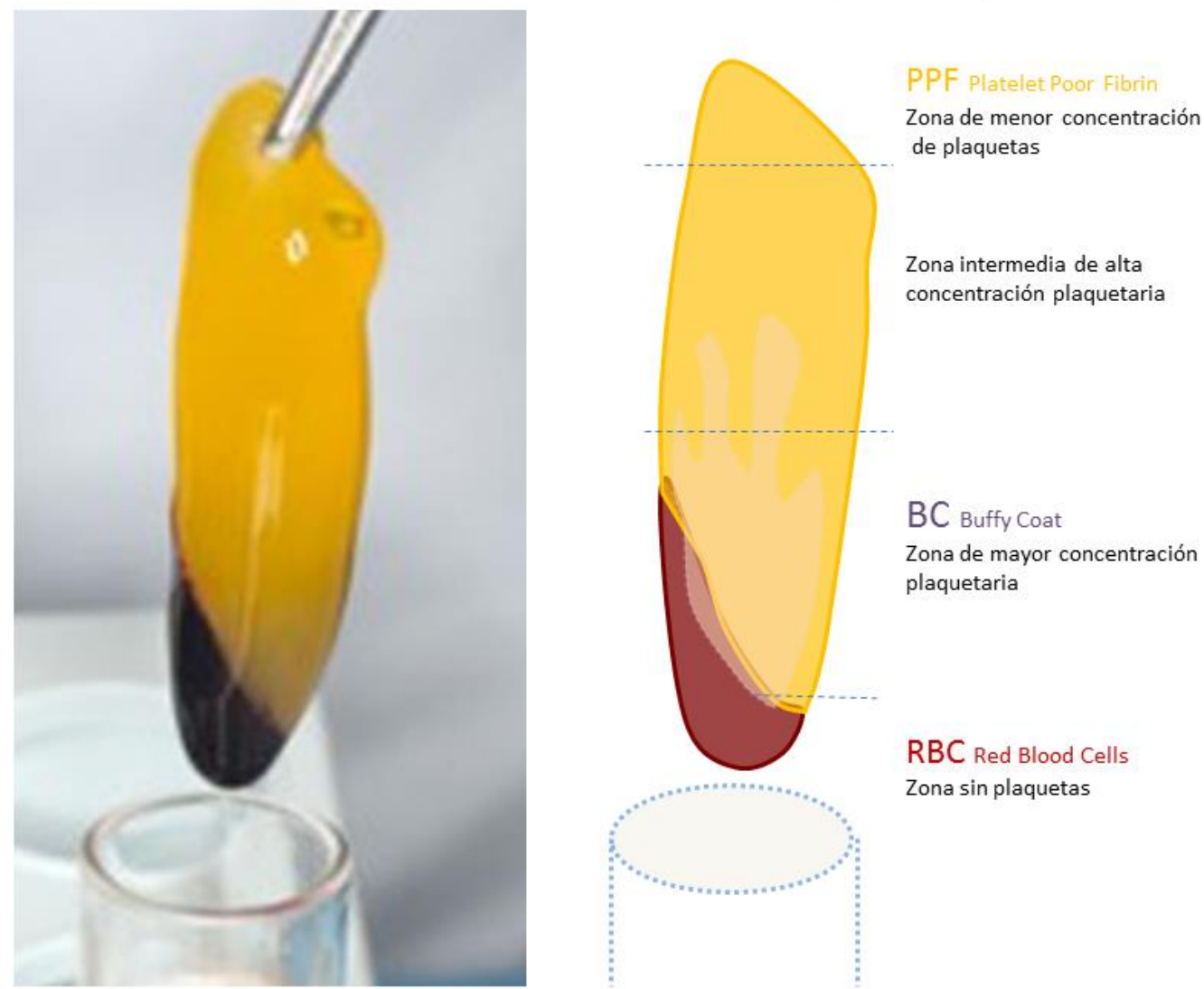

\section{Características Microscópicas}

En el análisis histológico se observó que no hay una distribución plaquetaria homogénea a lo largo de la membrana de PRF. En el FPP hay una menor concentración plaquetaria, en comparación con la zona inferior BC. En la RBC se observan capas de polimorfonucleares y eritrocitos. En cuanto a la fibrina, es homogénea en la mayoría del PRF con excepción de la zona más superior, que es un poco laxa (figura 2). 


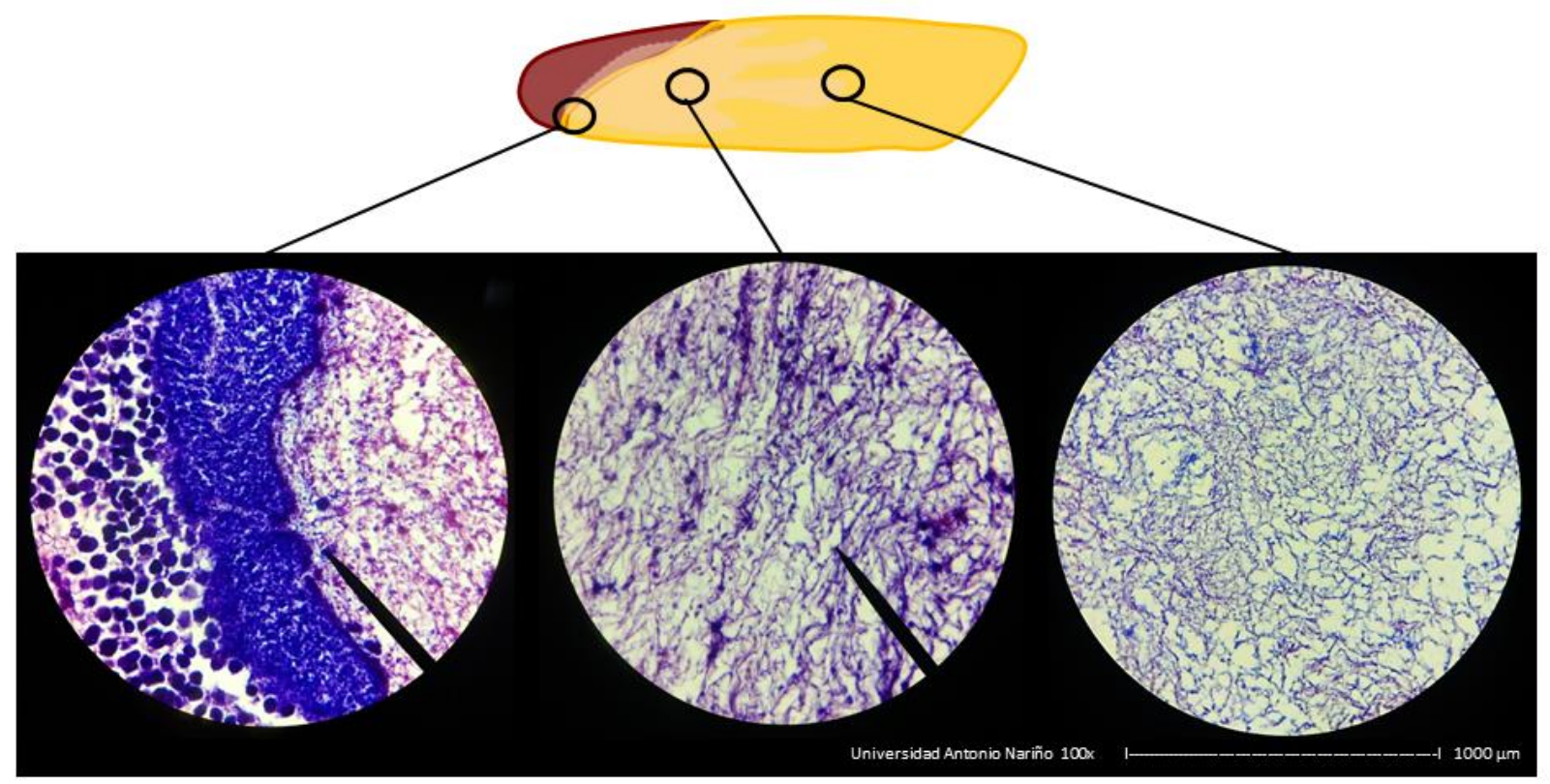

Tinción tricrómico de Masson (100x). Se observa la fibrina de color morado y las plaquetas de color azul

El análisis SEM comprueba que la estructura de la red de fibrina y que el contenido celular es diferente en las tres zonas de la membrana. Se observó que con el protocolo usado (10 minutos y $3.000 \mathrm{rpm}$ ) la concentración de plaquetas es mayor en la zona BC y disminuida en la zona PPF. De igual forma la fibrina en la zona BC es más densa (figura 3). 


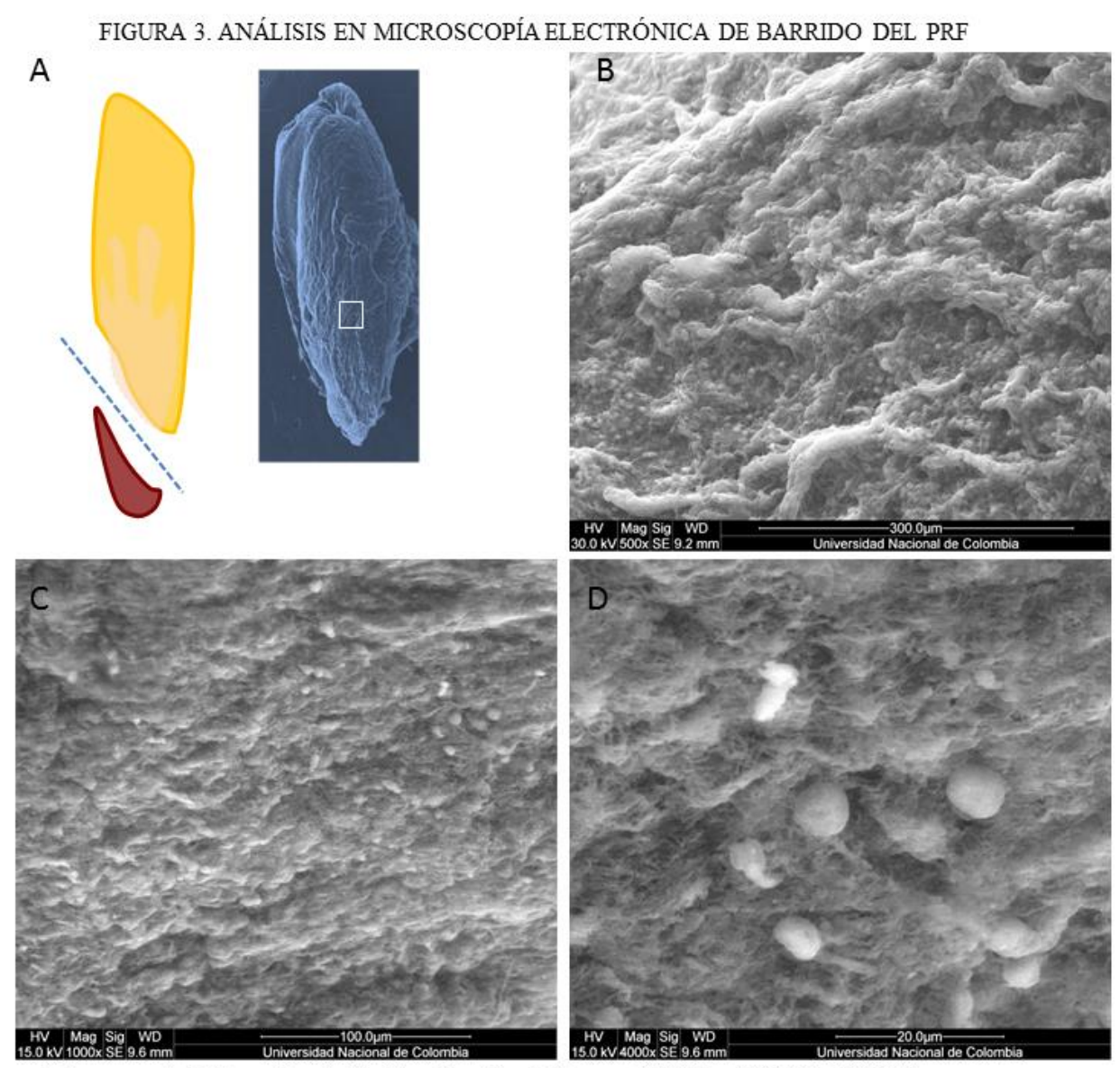

A. Esquema de PRF seccionado B. Magnificación de la zona BC 500x C. 1000x D. 4000x

Por otra parte, los resultados muestran que no hay diferencias en la concentración de plaquetas antes y después de compactar el PRF. Sin embargo, en cuanto a la red fibrina sí hay cambios, después de compactar el PRF y volverlo membrana, se observa histológicamente que la fibrina es más densa que el PRF sin compactar (figura 4a). En cuanto a los espacios interfibrinales en el gel se encontraron poros entre 8 y $22 \mu$ y en la membrana compactada se hallaron poros entre 4 y $12 \mu$. (figura 4b). 
FIGURA 4. FIBRINA RICA EN PLAQUETAS ANTES Y DESPUÉS DE COMPACTARSE. A) PRF GEL B) PRF MEMBRANA

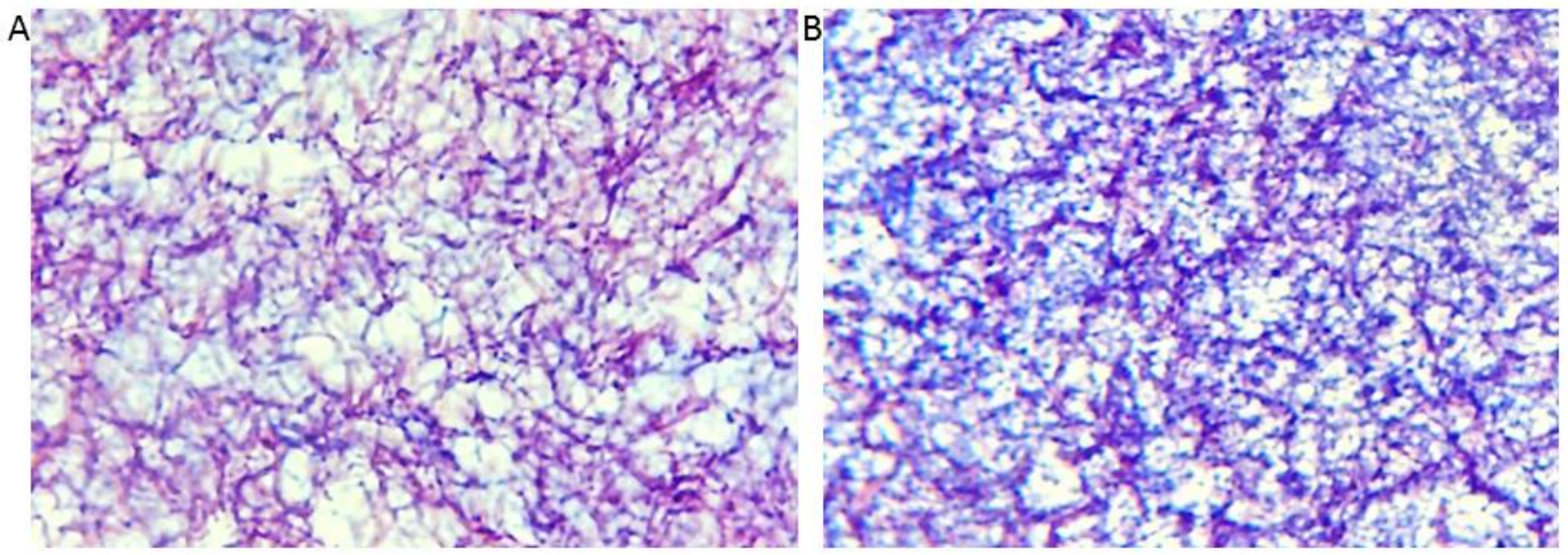

\section{DISCUSIÓN}

La fibrina rica en plaquetas PRF es un concentrado plaquetario que está siendo usado cada vez más en diferentes aplicaciones clínicas odontológicas (14). Los estudios muestran resultados variables (15), posiblemente asociados a la falta de estandarización de los diferentes protocolos empleados para su obtención, así como de las técnicas al momento de colocar el PRF en la zona requerida o al desconocimiento de los componentes estructurales de la membrana. El objetivo del presente estudio fue describir las características estructurales de la Fibrina Rica en Plaquetas en las diferentes zonas de la membrana. 
Actualmente, el PRF se usa en diferentes tratamientos clínicos odontológicos como por ejemplo en cirugías maxilofaciales que requieren reconstrucciones óseas severas $(16,17)$, en cirugías periodontales como alternativa al uso de injertos (18), en endodoncia para revitalización pulpar (19) y en apexificación de dientes inmaduros (20), entre otros. Aunque las aplicaciones clínicas son variadas, los reportes no describen con precisión la técnica, el tiempo post centrifugado, las condiciones de colocación del PRF, si se usa en membrana o gel, y en casos en que se requieren porciones muy pequeñas tampoco reportan el sitio o zona de donde se corta la membrana a usar. El presente estudió comprobó que el PRF tiene tres zonas, cada una con diferencias en el contenido celular. Las plaquetas y los leucocitos están más concentrados en la zona intermedia o BC, el área proximal a la zona corpuscular roja de cada membrana, siendo esta la zona más rica células (21) y es la ideal para usarse en aquellos tratamientos que no requieren grandes cantidades de PRF, es decir que, para aplicaciones endodónticas es más útil cortar y usar la porción de BC que de otras partes del PRF. Lo anterior debido a que el número de plaquetas y leucocitos está directamente relacionado con la expresión de moléculas como citoquinas y factores de crecimiento, entre otros, quienes estimulan la proliferación y diferenciación celular y por ende la regeneración tisular (22, 23), por lo que usar la zona como mayor concentración celular aumentaría el potencial regenerativo del PRF.

Contrariamente, la fibrina se distribuye a lo largo del PRF y aunque la polimerización se forma progresivamente, el resultado de la red es muy homogéneo. Esta característica le da una resistencia igualmente equilibrada en toda la estructura (21), lo que permite usar el PRF como membrana de protección o como una pared para soportar otros materiales, es decir no tiene ninguna limitación 
en cuanto a la ubicación o a la forma en que se coloque. Se puede usar en cirugías de perforaciones sinusales como una membrana (24), para colocarla como pared de protección en lesiones óseas para contener algún biomaterial, como por ejemplo en el manejo de fenestraciones (25), también se puede utilizar colocando otro biomaterial entre dos membranas (26).

De igual forma, acá se demostró que la compresión del PRF para generar una membrana no altera la concentración de plaquetas, similar a lo reportado por Kobayashi et al (27), en donde proponen la compactación del PRF como un paso a seguir dentro del protocolo. El presente estudio además describió una mayor densidad en la fibrina después de compactada, lo que comprueba la calidad del material para usarlo clínicamente como barrera.

Por otra parte, en los casos clínicos en que se requiere usar el PRF como un matriz o andamio celular para regeneración de tejidos en lesiones de moderadas a severas, lo ideal es tener una red laxa que permita la migración celular, con espacios adecuados al tamaño de las células que se esperan alojar (28). Posiblemente este evento celular de migración podría ser más fácil en el PRF sin compactar, que tiene espacios interfibrinales entre $8-22 \mu$ y la fibrina del PRF compactado es muy densa, con espacios inferiores a $8 \mu$.

También se puede utilizar el PRF de forma combinada, en gel para mantener una estructura y proveer espacio para que la regeneración tisular y además en membrana para posteriormente recubrir la lesión, mantener los tejidos y las estructuras de soporte, como en el caso del manejo de algunas lesiones orocutáneas (29), o en casos de manejo de elevación de seno, en donde se coloca 
el gel dentro de la cavidad sinusal y luego se recubre la ventana ósea con una membrana de $\operatorname{PRF}(30)$.

\section{CONCLUSIONES}

A partir del conocimiento estructural del PRF se pueden proponer aplicaciones que mejoren el rendimiento del material y por tanto los resultados clínicos. En cirugías donde se requiera utilizarse como membrana de protección para recubrir lesiones lo ideal es una estructura densa y compacta. Para procedimientos de regeneración de tejidos es preferible usar el PRF sin compactar y si es para lesiones de menos de un centímetro como en endodoncia, es mejor cortarlo de la zona BC.

\section{RECOMENDACIONES}

Los autores sugerimos realizar estudios con una muestra mayor que permita comparar varios protocolos de centrifugación para obtención de PRF y detallar los cambios estructurales, celulares y de expresión de factores de factores de crecimiento y citoquinas, en donde se pueda realizar una caracterización más precisa y útil para los usuarios que tienen dudas frente a los diferentes protocolos reportados.

\section{REFERENCIAS}

1. Amrollahi P, Shah B, Seifi A, Tayebi L. Recent advancements in regenerative dentistry: A review. Mater Sci Eng C Mater Biol Appl. 2016; 69: 1383-90. 
2. Choukroun J, Diss A, Simonpieri A, Girard MO, Schoeffler C, Dohan SL, et al. Platelet-rich fibrin (PRF): a second-generation platelet concentrate. Part IV: clinical effects on tissue healing. Oral Surg Oral Med Oral Pathol Oral Radiol Endod. 2006;101(3):e56-60.

3. Dohan Ehrenfest DM, Rasmusson L, Albrektsson T. Classification of platelet concentrates: from pure platelet-rich plasma (P-PRP) to leucocyte- and platelet-rich fibrin (L-PRF). Trends Biotechnol. 2009; 27(3): 158-67.

4. Borie E, Olivi DG, Orsi IA, Garlet K, Weber B, Beltran V, et al. Platelet-rich fibrin application in dentistry: a literature review. Int J Clin Exp Med. 2015; 8(5): 7922-9.

5. Tunali M, Ozdemir H, Kucukodaci Z, Akman S, Firatli E. In vivo evaluation of titaniumprepared platelet-rich fibrin (T-PRF): a new platelet concentrate. Br J Oral Maxillofac Surg. 2013; 51(5): 438-43.

6. Miron RJ, Fujioka-Kobayashi M, Bishara M, Zhang Y, Hernandez M, Choukroun J. PlateletRich Fibrin and Soft Tissue Wound Healing: A Systematic Review. Tissue Eng Part B Rev. 2017; 23(1): 83-99.

7. Dohan DM, Choukroun J, Diss A, Dohan SL, Dohan AJ, Mouhyi J, et al. Platelet-rich fibrin (PRF): a second-generation platelet concentrate. Part I: technological concepts and evolution. Oral Surg Oral Med Oral Pathol Oral Radiol Endod. 2006; 101(3): e37-44.

8. Dohan DM, Choukroun J, Diss A, Dohan SL, Dohan AJ, Mouhyi J, et al. Platelet-rich fibrin (PRF): a second-generation platelet concentrate. Part III: leucocyte activation: a new feature for platelet concentrates? Oral Surg Oral Med Oral Pathol Oral Radiol Endod. 2006; 101(3): e51-5. 
9. Eren G, Gurkan A, Atmaca H, Donmez A, Atilla G. Effect of centrifugation time on growth factor and MMP release of an experimental platelet-rich fibrin-type product. Platelets. 2016; 27(5): 427-32.

10. Dohan Ehrenfest DM, Pinto NR, Pereda A, Jimenez P, Corso MD, Kang BS, et al. The impact of the centrifuge characteristics and centrifugation protocols on the cells, growth factors, and fibrin architecture of a leukocyte- and platelet-rich fibrin (L-PRF) clot and membrane. Platelets. 2017: 1-14.

11. Gutiérrez D, Restrepo A, Hinojosa J, Muñoz A, Ortiz Y. Centrifugation protocols to obtain platelet rich fibrin for dental applications. Innov Odontol. 2016; 1(1): 18-22.

12. Acosta P, Gutiérrez S, Bedoya M, García A, Moreno X. Evaluation of platelet-rich plasma effect at different times and concentrations on periodontal ligament fibroblast and osteoblast viability. Univ Odontol. 2017; 36(76): 1-23.

13. Dohan Ehrenfest DM. How to optimize the preparation of leukocyte- and platelet-rich fibrin (L-PRF, Choukroun's technique) clots and membranes: introducing the PRF Box. Oral Surg Oral Med Oral Pathol Oral Radiol Endod. 110. United States2010. p. 275-8; author reply 8-80.

14. Kumar YR, Mohanty S, Verma M, Kaur RR, Bhatia P, Kumar VR, et al. Platelet-rich fibrin: the benefits. Br J Oral Maxillofac Surg. 2015.

15. Verma UP, Yadav RK, Dixit M, Gupta A. Platelet-rich Fibrin: A Paradigm in Periodontal Therapy - A Systematic Review. J Int Soc Prev Community Dent. 2017; 7(5): 227-33.

16. Del Corso M, Vervelle A, Simonpieri A, Jimbo R, Inchingolo F, Sammartino G, et al. Current knowledge and perspectives for the use of platelet-rich plasma (PRP) and platelet-rich fibrin (PRF) in oral and maxillofacial surgery part 1: Periodontal and dentoalveolar surgery. Curr Pharm Biotechnol. 2012; 13(7): 1207-30. 
17. Ranganathan AT, Chandran CR. Platelet-rich fibrin in the treatment of periodontal bone defects. J Contemp Dent Pract. 2014; 15(3): 372-5.

18. Thombre V, Koudale SB, Bhongade ML. Comparative evaluation of the effectiveness of coronally positioned flap with or without acellular dermal matrix allograft in the treatment of multiple marginal gingival recession defects. Int J Periodontics Restorative Dent. 2013; 33(3): e88-94.

19. Giraldo T, Sossa H. Endodoncia regenerativa: utilización de fibrina rica en plaquetas autóloga en dientes permanentes vitales con patología pulpar. Revisión narrativa de la literatura. Acta Odontológica colombiana [en línea]. 2014; 4(1): 91-112.

20. Faizuddin U, Solomon RV, Mattapathi J, Guniganti SS. Revitalization of traumatized immature tooth with platelet-rich fibrin. Contemp Clin Dent. 2015; 6(4): 574-6.

21. Dohan Ehrenfest DM, Del Corso M, Diss A, Mouhyi J, Charrier JB. Three-dimensional architecture and cell composition of a Choukroun's platelet-rich fibrin clot and membrane. J Periodontol. 2010; 81(4): 546-55.

22. Schar MO, Diaz-Romero J, Kohl S, Zumstein MA, Nesic D. Platelet-rich concentrates differentially release growth factors and induce cell migration in vitro. Clin Orthop Relat Res. 2015; 473(5): 1635-43.

23. Kobayashi E, Fluckiger L, Fujioka-Kobayashi M, Sawada K, Sculean A, Schaller B, et al. Comparative release of growth factors from PRP, PRF, and advanced-PRF. Clin Oral Investig. 2016; 20(9): 2353-2360.

24. Pinto G, Pigossi SC, Pessoa T, Nicoli LG, Araujo R, Marcantonio C, et al. Successful Use of Leukocyte Platelet-Rich Fibrin in the Healing of Sinus Membrane Perforation: A Case Report. Implant Dent. 2018. In press 
25. Bhatsange A, Shende A, Deshmukh S, Japatti S. Management of fenestration using bone allograft in conjunction with platelet-rich fibrin. J Indian Soc Periodontol. 2017; 21(4): 33740.

26. Johns DA, Shivashankar VY, Maroli RK, Joseph R. Invasive cervical root resorption: Engineering the lost tissue by regeneration. Contemp Clin Dent. 2013; 4(4): 536-9.

27. Kobayashi M, Kawase T, Horimizu M, Okuda K, Wolff LF, Yoshie H. A proposed protocol for the standardized preparation of PRF membranes for clinical use. Biologicals. 2012; 40(5): $323-9$.

28. Moradian H, Rafiee A, Ayatollahi M. Design and Fabrication of a Novel Transplant Combined with Human Bone Marrow Mesenchymal Stem Cells and Platelet-rich Fibrin: New Horizons for Periodontal Tissue Regeneration after Dental Trauma. Iran J Pharm Res. 2017; 16(4): 13708.

29. Bilginaylar K. Uncommon Odontogenic Orocutaneous Fistula of the Jaw Treated with PlateletRich Fibrin. Case Rep Dent. 2017; 2017: 7174217.

30. Aoki N, Kanayama T, Maeda M, Horii K, Miyamoto H, Wada K, et al. Sinus Augmentation by Platelet-Rich Fibrin Alone: A Report of Two Cases with Histological Examinations. Case Rep Dent. 2016; 2016: 2654645. 